\title{
Por um feminismo decolonial: a leitura antipatriarcal, anticapitalista, antirracista de Françoise Vergès
}

Toward a Decolonial Feminism: an Antipatriarchy, Anticapitalistic and Antiracist Reading of Françoise Vergès

\author{
Gilmara Joane Macêdo de Medeiros ${ }^{1}$ (iD 0000-0002-2526-0787 \\ 'Universidade Federal Rural do Semiárido, Centro de Ciências Sociais Aplicadas e \\ Humanas, Departamento de Ciências Sociais Aplicadas, Mossoró, RN, Brasil. \\ 59625-900 - dcsa@ufersa.edu.br
}

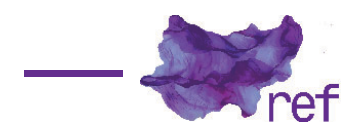

VERGÈS, Françoise.

Um feminismo decolonial.

Trad. de Jamille Pinheiro Dias e Raquel Camargo. São Paulo: Editora Ubu, 2020. 144p.

Em sua primeira obra traduzida no Brasil, Um feminismo decolonial, introduzida no mercado editorial pela Editora Ubu, a estudiosa Françoise Vergès ${ }^{1}$ (2020) expõe de maneira provocativa os elementos políticos e teóricos de desenvolvimento de um feminismo decolonial. A proposta em discussão - difundida no país a partir de outras intelectuais, tais como Lélia Gonzalez (2019), Orchy Curiel (2009), María Lugones (2014), Rita Laura Segato (2012), dentre outras -, apresenta-se como uma forma de intervir no mundo que questiona e aponta para as permanências e desigualdades provenientes do processo de colonização das Américas, da África e da Ásia, analisando os seus impactos nas vidas das mulheres negras e racializadas.

Trata-se de uma leitura que reivindica a radicalidade do feminismo como uma expressão da luta das mulheres do sul global ${ }^{2}$, situando-o como uma forma de oposição ao patriarcado, ao capitalismo e ao racismo-colonialismo, ao mesmo tempo em que aponta para as fragilidades do feminismo hegemônico - notadamente branco e liberal, a que autora denomina de civilizatório. Esta vertente reforça, para Vergès, o processo de exploração-dominação-opressão das mulheres colonizadas quando constrói uma perspectiva política travestida de um projeto de emancipação feminina, criado à luz de uma concepção pouco inclusiva de emancipação das mulheres.

\footnotetext{
${ }^{1}$ Françoise Vergès é uma feminista, cientista política, historiadora, ativista e especialista em estudos pós-coloniais. Nascida num Departamento Ultramarino francês no Oceano Índico - a llha da Reunião.

2 Norte/sul é uma nomenclatura utilizada na área das ciências sociais para demarcar a divisão global entre os países colonizadores e imperialistas (em especial, os Estados Europeus) daqueles que sofreram com o processo de espoliação, expropriação e exploração por eles realizado - desde o século XV - também chamados de países colonizados. A esse respeito, ver: Boaventura de Sousa Santos (2009). SANTOS, Boaventura de Sousa. "Para além do pensamento abissal: das linhas globais a uma ecologia de saberes". In: SANTOS, Boaventura de Sousa; MENESES, Maria Paula. Epistemologias do sul. Coimbra: Edições Almedina, 2009. p. 23-71.
} 
Para o desenvolvimento mais apurado de sua análise, a estudiosa volta suas reflexões ao trabalho invisível de limpeza realizado no mundo capitalista, no qual o recolhimento do lixo e o saneamento dos espaços públicos e privados são executados, majoritariamente, por mulheres negras e racializadas ${ }^{3}$. Cotidianamente elas abrem as cidades, limpam os espaços utilizados pelos/as demais, são expostas a produtos químicos, à contaminação do lixo e ao esgotamento de sua energia vital; são indispensáveis para o funcionamento da sociedade contemporânea - considerada uma produtora de dejetos e supérfluos, tanto com relação às coisas quanto aos próprios seres humanos.

Tão indispensáveis que, mesmo em tempos disruptivos como o que vivenciamos em 2020 e 2021 - em razão da pandemia de Covid-19 -, estas mulheres permaneceram/em desenvolvendo as atividades de limpeza pública e privada, abastecendo os mercados; seus filhos/as, pais e, porventura, companheiros/as, também negros/as e racializados/as, são, em sua maioria, aqueles que mantiveram/mantêm os serviços de delivery, transporte e abastecimento das cidades em plena quarentena. Não à toa, a população periférica e negra já é a mais atingida pela doença e por sua face reveladora da desigualdade social em países como o Brasil e Estados Unidos, por exemplo.

Na perspectiva de Vergès, o trabalho de recolher os dejetos do mundo funciona também como um símbolo da descartabilidade dos corpos e vidas das mulheres negras e racializadas, promovida pelo imbricamento entre patriarcado-racismo-capitalismo, reforçados pelo colonialismo. Nas suas palavras "[...] a economia de produção de lixo é inseparável da produção de seres humanos fabricados como 'sucata', como 'lixo'” (VERGÈS, 2020, p. 127).

O colonialismo, como nos adverte a estudiosa, não pode ser confundido com a colonização, uma vez que se trata de um processo/movimento que se perpetua através das relações sociais desiguais e de dominação, constituídas por séculos de colonização de determinados corpos e territórios.

A colonialidade, como uma expressão de poder, pode ser percebida no ocultamento da história dos povos colonizados e na invisibilidade de suas lutas, memórias e vidas nas reflexões teóricas produzidas pela academia - predominantemente branca e eurocêntrica. Contar a história das mulheres e dos povos colonizados, de suas resistências, conhecimentos e culturas significa não apenas promover a reparação de sua memória e dignidade, mas também se insurgir contra o processo de colonização que permanece na difusão de saberes eurocentrados.

É nesse sentido que Vergès reivindica a importância de um feminismo decolonial. A estudiosa compreende que uma perspectiva radical do feminismo deve ser questionadora do modo de produção social no qual vivemos, buscando construir alternativas emancipatórias para a existência de mulheres e homens no mundo. A seu ver, a grande tarefa deste feminismo é a de pensar a respeito dos desafios impostos a uma humanidade ameaçada de desaparecer; representa-se na recusa ao modo de vida que nos transforma em supérfluos, em números manipuláveis nos cálculos de risco das grandes corporações e de sua manipulação financeira, em corpos matáveis, em objetos do encarceramento massivo, em bárbaros/as a serem salvos/as pela redentora política desenvolvimentista da civilização.

Não se trata de uma "quarta onda" do feminismo ${ }^{4}$, mas de uma intensificação da luta das mulheres negras e racializadas no processo contínuo de libertação dos povos. Trata-se de reconhecer a centralidade destas lutas na reflexão política e no abandono dos pressupostos civilizatórios partilhados por toda e qualquer perspectiva que não reconheça o processo de dominação do sul global, provocados pelos séculos de colonização. Ou, como prefere chamar a estudiosa, diz respeito ao desenvolvimento de um feminismo ancorado na quilombagem ${ }^{5}$, isto é, numa promessa radical de transformação do mundo, ainda que todos os horizontes para sua mudança pareçam improváveis e sejam negados pela lei, pelo Estado e pela economia.

A edição brasileira está dividida em dois capítulos. A obra também contém um texto de apresentação da Flávia Rios (2020) intitulado "Por um feminismo radical", bem como uma nota de tradução das tradutoras Jamille Pinheiro Dias e Raquel Camargo. Além disto, possui um prefácio escrito especialmente para a edição brasileira e uma introdução chamada de "Invisíveis, elas abrem a cidade".

No primeiro capítulo, Vergès busca definir o que compreende ser um feminismo decolonial e sua metodologia. A seu ver, ele nasce das vozes e das experiências concretas das mulheres negras, indígenas e racializadas, a partir de seus movimentos de resistência na

\footnotetext{
${ }^{3}$ A estudiosa utiliza a expressão racializadas para se referir às mulheres pertencentes a minorias étnicas, religiosas e migrantes.

${ }^{4}$ Nesse sentido, a preocupação de Vergès (2020) é a de indicar que não se trata de uma nova face do feminismo, mas de uma reflexão e de um aprofundamento construído a partir das lutas das mulheres negras e racializadas, no aprendizado contínuo e no amadurecimento que tiveram dentro dos mais amplos movimentos de libertação dos povos (movimentos de independência, movimentos negros e indígenas, de camponesas, dentre outros).

${ }^{5}$ Por quilombagem Vergès (2020, p. 49) compreende ser todos "[...] os gestos, cantos, rituais que noite e dia, escondidos ou visíveis, representam uma promessa radical. A quilombagem afirmava a possibilidade de um futuro mesmo quando ele era negado pela lei, pela Igreja, pelo Estado e pela cultura [...]".
} 
própria história e na sua luta por evidenciar as particularidades e permanências da colonização sobre os seus corpos. Esta práxis reivindica uma pedagogia da transversalidade, promovendo uma análise multidimensional das opressões sociais; pedagogia que se desenvolve na recusa por enquadrar raça/etnia, classe e sexualidade como categorias mutuamente excludentes, bem como no rechaçamento de qualquer tentativa de hierarquizá-las. Desta forma, o método feminista decolonial evita a segmentação - concebida como uma forma própria dos estudos sociais ocidentais - propondo em seu lugar análises que revelem o ecossistema social e sua teia exploratória e discriminatória.

Esta forma de insurgência também questiona o próprio cânone feminista. Ao analisar as origens do feminismo liberal, Vergès resgata os seus elementos civilizatórios, presentes até os dias atuais na busca por universalizar uma concepção de mulher e de feminilidade, ignorando as múltiplas vivências das mulheres em nossa sociedade 6 . A autora tece críticas, em especial, ao feminismo europeu (sobretudo, ao francês) que, muitas vezes, recusa-se a admitir a presença do racismo em seus filões e em suas análises, construindo estratégias cegas com relação à raça. Neste ponto, busca compreender como as mulheres brancas e o ideal de feminilidade que as aprisiona(ra)m também foram moldados pela colonização, enfatizando que um dos impactos deste processo em suas vidas é justamente o não reconhecimento do problema racial e da ideologia civilizatória em seus discursos e lutas.

Vergès mostra-se bastante crítica a algumas estratégias apoiadas pelo feminismo hegemônico e difundidas globalmente como uma política de emancipação das mulheres, sobretudo por meio da atuação de órgãos multilaterais, tais como o Banco Mundial e o Fundo Monetário Internacional (FMI), bem como pela Organização das Nações Unidas (ONU). Refere-se à alternativa desenvolvimentista que incentivou a autonomia feminina por meio da concessão de microcrédito, que estimulou a criação de Organizações Não-governamentais como modelo associativo e a adoção de um linguajar pouco crítico com relação ao modelo neoliberal que se expandia globalmente aliado a tais recursos. Modelo que resultou numa hiper exploração da mão-de-obra das mulheres do sul global e na expansão da violência articulada do capitalpatriarcado-racismo?.

No segundo capítulo, a estudiosa aprofunda sua análise sobre como as políticas acima mencionadas impactaram a vida das mulheres negras, indígenas e racializadas, evidenciando o aspecto pouco transformador do feminismo hegemônico e do modelo de inclusão liberal por ele proposto e difundido. A seu ver, a adoção desta perspectiva e sua propagação é uma das faces da continuidade do processo civilizador iniciado pela colonização, que incentiva as mulheres do sul global a se ocuparem cada vez mais das funções reprodutivas e dos serviços de cuidado em nossas sociedades.

Para além disto, Vergès discute a conjuntura do feminismo francês e do crescimento do racismo entre suas ativistas, incluindo a apropriação de aspectos do feminismo por asseclas da extrema direita europeia, ao que ela denomina de femonacionalismo. Racismo que se disfarça na defesa da república francesa e da laicidade do Estado, isto é, a proteção da civilização em oposição aos estrangeiros bárbaros. Refere-se aqui, em especial, à querela do véu islâmico e a campanha pela proibição de sua utilização nas escolas francesas, encampada por algumas figuras históricas do feminismo francês. A seu ver, esta atitude promove a xenofobia e aparenta que a outra, a estrangeira precisa da ação das corajosas mulheres brancas para compreender o verdadeiro significado da emancipação feminina. Além disto, reforça a construção social do inimigo, do homem negro e racializado como naturalmente violento, um estuprador em potencial ${ }^{8}$ etc.

A autora ainda destaca o fato de que o feminismo hegemônico quando busca a incorporação das mulheres negras e racializadas no seu panteão, acaba por despolitizá-las, retirando o caráter comunitário e social de suas lutas e atividades, transformando-as em heroínas, em sujeitas singulares. Neste sentido, destaca que uma das tarefas do feminismo decolonial é a de se esforçar para recuperar as histórias das mulheres escravizadas, negras e racializadas, evitando a despolitização de suas figuras e o seu deslocamento como símbolos de uma luta coletiva.

Vergès encerra sua obra provocando algumas reflexões acerca dos desafios enfrentados pelo feminismo decolonial. Para ela, é preciso construir a luta de emancipação das mulheres em permanente solidariedade com os homens negros e racializados, uma vez que eles também são vítimas e produtos do sistema global. É preciso também politizar o cuidado e questionar a racialização do trabalho reprodutivo, questionando-se permanentemente sobre quais são os

\footnotetext{
${ }^{6}$ Crítica que também pode ser encontrada em Angela Davis (2016) em suas análises sobre a relação entre o movimento sufragista e o abolicionista nos EUA. DAVIS, Angela. Mulheres, raça e classe. Trad. de Heci Regina Cardiani. São Paulo: Boitempo, 2016.

${ }^{7}$ Uma importante contribuição acadêmica, neste sentido, é a de Rita Laura Segato (2012), em especial, quando se debruçou sobre o feminicídio na fronteira México e Estados Unidos.

${ }^{8}$ Aspecto também analisado por Angela Davis (2016).
} 
corpos cujas vidas são exauridas pelo trabalho, perguntando-se sobre quem limpa o mundo e qual a relação entre o lixo humano e o/a humano/a lixo. Por fim, é preciso reconectarmo-nos com a potência imaginativa do feminismo, isto é, restaurar a força criativa da insubmissão.

\section{Referências}

CURIEL, Orchy. Descolonizando el feminismo: una perspectiva desde América Latina y el Caribe. Coordinadora Feminista. 16/12/2009. Disponível em: http://feministas.org/descolonizando-elfeminismo-una.html. Acesso em: 08/06/2020.

GONZALEZ, Lélia. "A categoria político-cultural da Amerifricanidade". In: HOLLANDA, Heloisa Buarque de (org.). Pensamento Feminista: conceitos fundamentais. Rio de Janeiro: Bazar do tempo, 2019. p. 341-352.

LUGONES, María. "Rumo a um feminismo descolonial". Revista Estudos Feministas, Florianópolis, v. 22, n. 3, p. 935-952, set.-dez. 2014.

RIOS, Flávia. Por um feminismo radical. In: VERGÈS, Françoise. Um feminismo decolonial. Trad. de Jamille Pinheiro Dias e Raquel Camargo. São Paulo: Editora Ubu, 2020. p. 10-18.

SEGATO, Rita Laura. "Gênero e colonialidade: em busca de chaves de leitura e de um vocabulário estratégico descolonial". e-cadernos ces [Online], 18, 2012. Disponível em: http://eces.revues. org/1533. Acesso em: 08/06/2020.

VERGÈS, Françoise. Um feminismo decolonial. Trad. de Jamille Pinheiro Dias e Raquel Camargo. São Paulo: Editora Ubu, 2020.

Gilmara Joane Macêdo de Medeiros (gilmara.medeiros@ufersa.edu.br) é professora do curso de Direito da Universidade Federal Rural do Semiárido (UFERSA), Doutora em Direito pela Universidade de Brasília (UnB), Mestra e Graduada em Ciências Jurídicas pela Universidade Federal da Paraíba (UFPB). Coordena o Centro de Referência em Direitos Humanos do Semiárido, desenvolvendo pesquisas na interface entre direitos humanos, direitos das mulheres e feminismos.

\section{COMO CITAR ESTE ARTIGO DE ACORDO COM AS NORMAS DA REVISTA}

MEDEIROS, Gilmara Joane Macedo de. "Por um feminismo decolonial: a leitura antipatriarcal, anticapitalista antirracista de Françoise Vergès". Revista Estudos Feministas, Florianópolis, v. 29, n. 2, e74626, 2021

\section{CONTRIBUIÇĀO DE AUTORIA}

Não se aplica.

\section{FINANCIAMENTO}

Não se aplica.

\section{CONSENTIMENTO DE USO DE IMAGEM}

Não se aplica.

\section{APROVAÇĀO DE COMITÊ DE ÉTICA EM PESQUISA}

Não se aplica.

\section{CONFLITO DE INTERESSES}

Não se aplica.

\section{LICENÇA DE USO}

Este artigo está licenciado sob a Licença Creative Commons CC-BY 4.0 International. Com essa licença você pode compartilhar, adaptar, criar para qualquer fim, desde que atribua a autoria da obra.

\section{HISTÓRICO}

